DOI: 10.11606/issn.2238-3867.v17i2p397-406

sala preta

ppgac

Dossiê Branco: o cheiro do lírio e do formol

\title{
Cor ou Ele escreveu um texto sobre a peça dos brancos
}

Color or He wrote a text about the white's play

\section{Conrado Dess}

Conrado Dess

Graduando em Artes Cênicas pela Escola de Comunicações e Artes da Universidade de São Paulo e diretor e dramaturgo do grupo Performatron.

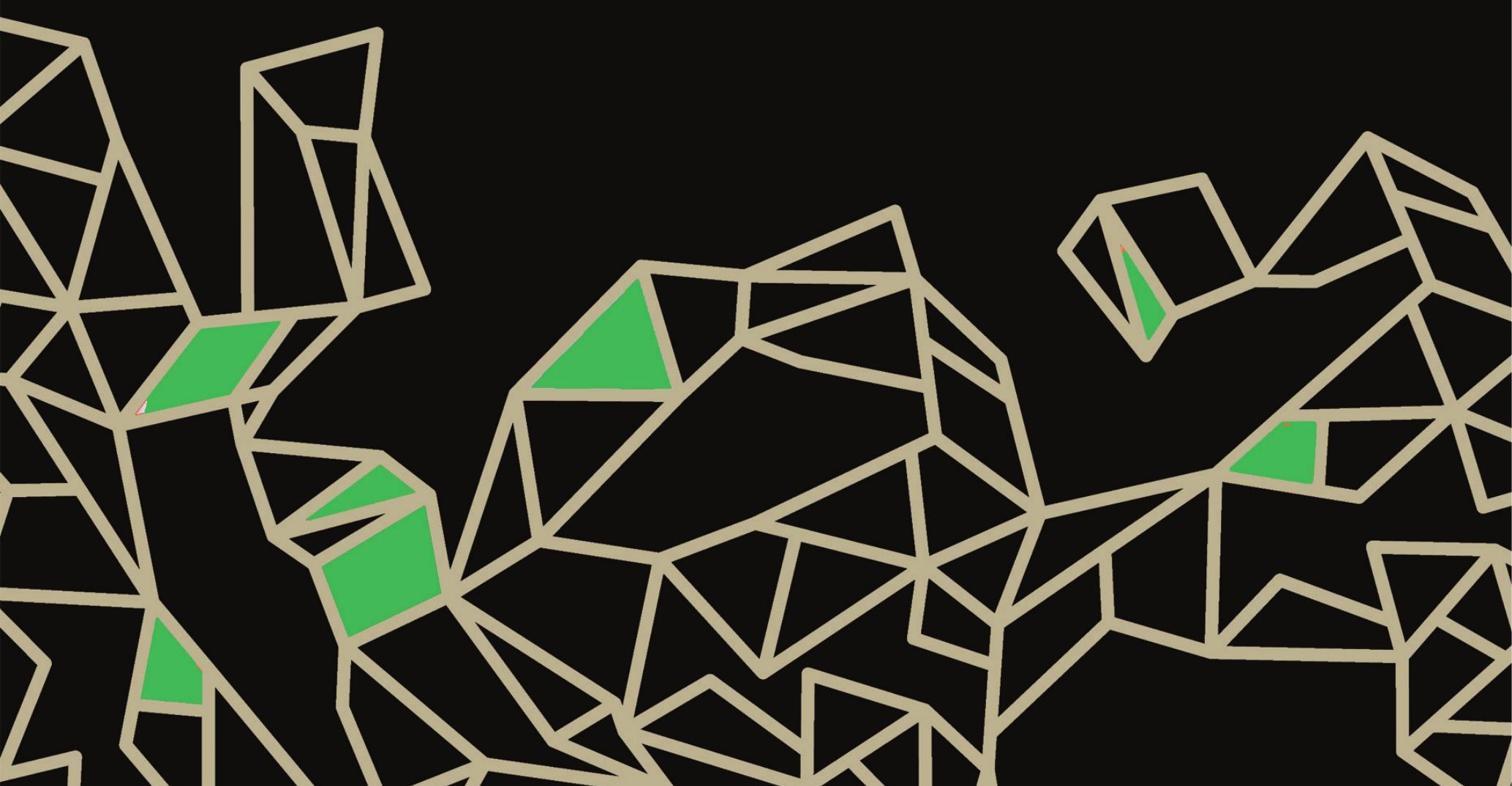




\section{Resumo}

Este ensaio propõe uma reflexão a respeito das implicações dos conceitos de negritude e branquitude na produção artística nacional, a partir da análise do espetáculo Branco: o cheiro do lírio e do formol. Pretende-se, ainda, desenvolver uma elaboração sobre a construção dramatúrgica e estética do espetáculo, bem como sobre os diálogos possíveis entre a obra e a situação política e social do Brasil atual.

Palavras-chave: Negritude, Branquitude, Teatro negro, Teatro branco, Racismo.

\section{Abstract}

This essay proposes a reflection on the implications of the concepts of blackness and whiteness in the national artistic production, from the analysis of the play Branco: o cheiro do lírio e do formol. It is also intended to develop an elaboration on the dramaturgical and aesthetic construction of the play, as well as on the possible dialogues between the piece and the current political and social situation in Brazil.

Keywords: Blackness, Whiteness, Black theater, White Theater, Racism.

Uma obra de arte não existe jamais sozinha, ela é sobretudo o sistema que a torna possível e particularmente o sistema que identifica a ideia à realidade, a arte à vida. Gaston Fernandez Carrera

Como o próprio título já diz, há algo de morto no espetáculo Branco: o cheiro do lírio e do formol. A peça escrita pelo dramaturgo Alexandre Dal Farra, que divide com Janaina Leite a direção do trabalho, constitui-se como uma tentativa de enfrentamento da questão do racismo pelo viés da branquitude. Viés esse que se apresenta como uma alternativa possível a partir do momento em que se opta por excluir o negro da discussão - ou da cena. Cabe, no entanto, ao artista e ao espectador que se propõe a adentrar um ponto tão nevrálgico, como é o racismo na sociedade brasileira, defrontar-se com as possíveis implicações políticas e sociais da obra artística. Trata-se de experienciar a potência do risco. O risco do erro, do acerto ou da queda. 
Em Branco, a queda é violenta e faz sangrar feridas que se encontram ainda muito distantes de serem cicatrizadas.

Deslocar o eixo de observação na discussão sobre o racismo é um exercício ainda pouco explorado na produção artística nacional. Observamos, no entanto, desde Abdias do Nascimento e seu Teatro Experimental do Negro, até grupos contemporâneos como o Bando de Teatro Olodum, o Coletivo Negro e a Capulanas Cia. de Arte Negra, entre outros, o esforço do artista teatral negro em desenvolver espaços próprios para criação, que possibilitem o aprofundamento de sua pesquisa artística e o desenvolvimento de ações políticas para o combate ao racismo. Diante do problema que envolve as relações raciais no Brasil e da urgência que permeia a questão, o trabalho desenvolvido pelos grupos de teatro negro ${ }^{1}$ vem se consolidando como um importante instrumento de luta e resistência social.

No Brasil, desfruta-se de uma realidade capaz de instaurar a falsa sensação de que o racismo não existe ou tem poucas implicações no cotidiano da população negra. Como ressalta a psicóloga Lia Vainer Schucman (2014): "O racismo brasileiro tem a especificidade de, em maior ou menor grau, ser velado e sutil. A 'democracia racial'² faz parte do imaginário do brasileiro e constrói um ideal do qual os brasileiros, em sua maioria, não abrem mão" (p. 92). Diante de tal conjuntura, reafirma-se a necessidade de artistas, espectadores e críticos negros se posicionarem como detentores de um discurso legítimo e fundamental na discussão sobre o racismo. Nesse cenário, a utilização do termo teatro negro e sua própria organização como movimento artístico de afirmação da cultura negra refuta possíveis interpretações categorizantes e assume uma postura política de resistência, como pontua Evani Tavares Lima (2011):

1 O termo é utilizado aqui como propõe Lima (2011): conjunto de manifestações espetaculares negro-mestiças, originadas na Diáspora, que lança mão do repertório cultural e estético de matriz africana, como meio de expressão, recuperação, resistência e afirmação da cultura negra.

2 Schucman (2014) toma o termo "democracia racial" de acordo com a concepção de Hasenbalg: "uma arma ideológica produzida por intelectuais das elites dominantes brancas, destinada a socializar a população brasileira de brancos e não brancos como iguais, evitando, assim, um conflito racial no Brasil" (p. 92). 
O teatro negro brasileiro, além de lidar com questões derivadas de sua condição política (afirmar seu discurso e combater o que contradiz), ainda tem que justificar a necessidade de sua própria existência. Ora, é a sua própria existência, em condição de resistência, que justifica sua necessidade. Necessidade de preencher lacunas, tais como a ausência de atores, autores, textos e personagens negras, livres de estereótipos e da coisificação. Necessidade de mais fôlego e forças para renascer e conseguir sobrepor-se à, ainda nebulosa, identidade racial brasileira. (p. 84)

Contrapondo-se a esse teatro negro, que se propõe a discutir o problema do racismo por uma questão de sobrevivência, Branco: o cheiro do lírio e do formol assume sua condição de "teatro branco" para adentrar a mesma discussão, mas por motivos e meios fundamentalmente diferentes. Schucman (2014) destaca o modo como Guerreiro Ramos (1957) questiona os estudos sobre o negro desenvolvidos pela sociologia e pela antropologia brasileira. Para o autor, essas tomaram o negro apenas como tema e objeto de investigações e, portanto, tornaram-no simplesmente objeto de estudo e não sujeito. Assim o autor descreve:

Há o tema do negro e há a vida do negro. Como tema, o negro tem sido, entre nós, objeto de especulação perpetrada por literatos e pelos chamados "antropólogos" e sociólogos". Como vida ou realidade efetiva, o negro vem assumindo seu destino, vem fazendo a si próprio, segundo Ihe têm permitido as condições particulares da sociedade brasileira. Mas uma coisa é negro-tema; outra é negro-vida. O negro-tema é uma coisa examinada, olhada, vista, ora como ser mumificado, ora como ser curioso ou de qualquer modo como um risco, um traço da realidade nacional que chama a atenção. O negro-vida é, entretanto, algo que não se deixa imobilizar; é despistador, proteico, multiforme, do qual na verdade, não se pode dar versão definitiva, pois é hoje o que não era ontem e será amanhã o que não é hoje. (RAMOS, 1957, p. 171 apud SCHUCMAN, 2014, p. 54)

Nas artes, grupos como os acima citados vêm há algum tempo se aprofundando na pesquisa teatral da temática racial a partir de sua condição inerente de negro-vida. Trata-se da construção de um espaço onde o negro e sua condição política possam assumir o protagonismo de uma produção artística que muitas vezes lhe é negada. Nesse contexto, que espaço pode o branco 
ocupar nessa discussão? O que emerge de um espetáculo que discute o racismo sem a presença do negro? Teria chegado o momento em que, assim como na sociologia e na antropologia, o branco começa a deixar de olhar para o negro que sofre o racismo e passa a olhar para o branco que pratica o racismo? São essas algumas das questões que permeiam o espetáculo de Dal Farra.

É evidente que diante das complexidades que envolvem o racismo no Brasil e do pioneirismo que uma pesquisa teatral nesse sentido configura, sejam encontradas inúmeras dificuldades estéticas, formais e conteudísticas na condução desse processo. O que vemos em Branco é justamente a exposição de um processo de busca-tentativa-fracasso que acaba por revelar as dificuldades intrínsecas do processo de dissecação do racismo nas identidades raciais brancas.

Considerando as singularidades do racismo brasileiro anteriormente citadas, há de se partir do conceito fundante na construção do espetáculo: a branquitude. Schucman (2014) aponta a branquitude como uma posição em que os sujeitos que ocupam a posição social de brancos são sistematicamente privilegiados no que diz respeito ao acesso a recursos materiais e simbólicos, gerados inicialmente pelo colonialismo e pelo imperialismo, e que se mantêm e são preservados na contemporaneidade.

Nessa perspectiva, tornar a branquitude visível se caracteriza como o pilar essencial de uma discussão sobre o racismo. Há de se desconstruir a aura normatizante que envolve o conceito e colocá-lo em xeque, buscando deslocar sua centralidade artificial e lançá-lo na posição de objeto de análise crítica. Utilizando-se da linguagem cinematográfica como exemplo, Vron Ware (2014) faz importantes colocações sobre as implicações da branquitude nas produções artísticas contemporâneas:

Muitas vezes, a economia racial dessa cultura visualíssima oferece uma definição de branquidade como uma tela enganosamente branca, contra a qual se destacam em silhueta as construções da negritude e de outras formas de não-branquidade. Richard Dyer, cujo trabalho sobre o poder de representação da branquidade ilustrou esplendidamente seu caráter de tudo ou nada, foi o primeiro a defender essa ideia de modo convincente, analisando o que chamou de técnica estética do cinema, além de elementos mais óbvios da composição de personagens, da trama e do 
gênero. A branquidade pode tornar-se invisível para todos os que são apanhados em seu clarão ofuscante, disse ele. Vista por um ângulo, ela se afigura o estado normal e universal do ser, o padrão pelo qual todo o resto é medido e em cotejo com o qual todos os desvios são avaliados. (p. 16)

Branco é um espetáculo que almeja, de inúmeras maneiras, neutralizar o clarão ofuscante que torna a branquitude invisível e o meio encontrado para isso é justamente lançar luz sobre ela. Busca-se compreender a maneira como o racismo se instaura nos pequenos detalhes, no micro, tão inteligentemente diluído nas relações sociais que pode passar, e geralmente passa, despercebido.

Em cena, camadas dramatúrgicas se sucedem, sinalizando o vislumbre de um todo que nunca é passível de materialização. Na camada mais dramática, uma família disfuncional sobrevive ao esvaziamento de suas subjetividades. Em meio a colocações banais, debatem-se situações corriqueiras que, diante da qualidade metafórica do texto, são levemente deslocadas da cotidianidade familiar e lançadas ao estranhamento. Naquela família, um pai segura por muito tempo um carregador de celular desconectado e fala com apatia sobre coisas que tem vontade de fazer, uma tia com pernas inquietas masca chiclete incessantemente e um menino com corpo de homem e traços de ansiedade relata acontecimentos íntimos de sua existência. Todos falam, ninguém dialoga verdadeiramente. Em vários momentos, o vômito branco que escorre pela boca dos atores parece concretizar a imagem simbólica do discurso daquela família e a própria crítica contida no texto.

O que se sobressai ali é a materialidade do que é vazio. Em meio a um sistema onde o racismo é tão sofisticadamente diluído, as relações e os discursos que permeiam aqueles personagens esboçam a silhueta de algo maior, sem nunca revelar, no entanto, a matéria que a constitui. O que precipita desse processo é justamente a metáfora de comportamentos racistas tão bem arranjados que se tornam difíceis de serem acessados em sua estrutura. Em dado momento do espetáculo, o menino fala sobre como vomitou em uma reunião de bairro e sobre como sua ação o levou do constrangimento ao orgulho, até a conquista do objetivo desejado e, então, ao mal-estar novamente. Que vômito é esse capaz constranger, orgulhar e provocar implicações 
sociais? Trata-se ali da exposição do que existe de mais intrínseco àquelas pessoas. Trata-se do que é expelido voluntariamente ou involuntariamente e, cedo ou tarde, provocará consequências. Essa família, apesar de não atingir em nenhum momento sua concretude como célula social, proporciona um reflexo dos sistemas políticos, históricos e socioculturais que a compõem ou a atravessam.

Em paralelo, trechos de versões anteriores do espetáculo são apresentados encenados ou por meio de vídeos. Nesse momento são dois os planos que se desdobram, o da fábula contida no texto abandonado e o documental, instituído pela gravação audiovisual. A utilização do vídeo resvala aqui no campo do documentário, marca do trabalho já desenvolvido por Janaina Leite em outros espetáculos, e apresenta ao público, que testemunha, impotente, o registro de um processo conturbado, pautado pela autocrítica e a reavaliação. Quando adentramos a terceira camada dramatúrgica, aquela em que a voz lírica do autor se alterna entre relatos sobre a morte de seu pai e sobre suas dificuldades na criação do espetáculo, faz-se material o peso da ausência de uma das partes fundamentais nessa discussão.

Ware (2014) afirma que a negritude e a branquitude não podem ser separadamente analisadas, e isso se aplica em particular aos filmes em que a raça está aplicada na narrativa estruturante, definindo os personagens ou simplesmente funcionando como a presença da ausência. Em Branco, explicita-se a incapacidade de dar espaço ao outro, negro, e justifica-se essa opção como uma possibilidade de presença. A partir do momento, porém, em que a impossibilidade de presentificar o outro se instaura, o que precipita pode não ser uma presença pela ausência, mas a reprodução de um sistema historicamente excludente.

Entendendo a branquitude como um constructo ideológico de poder, em que os brancos tomam sua identidade racial como norma e padrão, e dessa forma outros grupos aparecem ora como margem, ora como desviantes, ora ainda como inferiores (Schucman, 2014), ela se constitui como um elemento que não necessita do outro, negro, para manifestar-se, uma vez que se entende como norma e nega a racialização que lhe é inerente. Em contraponto, a negritude só pode existir diante da necessidade de defesa de uma 
coletividade muitas vezes apagada, neutralizada pelo outro, como explana o excerto a seguir:

Há que se pensar que a construção da negritude é uma escolha feita por sujeitos negros. Porém, como toda e qualquer escolha, no sentido que Ihe atribui Sartre (1984), o sujeito atua sobre seu contexto a partir de determinadas condições objetivas que o precedem, devidamente situado dentro de determinada gama de opções. Essa escolha é o resultado induzido de uma série complexa de dialéticas em que, a partir de um estado original, relacionado à cor da pele negra, a traços físicos, ao status social e ao passado dos ancestrais africanos, o homem negro é remetido a si mesmo pelos outros e desta forma atua no mundo confirmando e produzindo sentidos singulares para a negritude. (SCHUCMAN, 2014, p. 88)

Tomando assim a negritude como um constructo que se desenvolve a partir da resposta à visão de um outro - branco - sobre ela, esse outro se faz sempre presente em sua constituição. O mesmo não se pode aferir sobre a branquitude, visto que essa não apenas nega, uma vez que negar ainda pressupõe a existência de um outro, mas sobretudo coloca-se indiferente e imune ao sistema racial que a constitui, e é justamente aí que reside o elemento estrutural do racismo ${ }^{3}$.

Ao negar a presença do outro, negro, Branco: o cheiro do lírio e do formol resvala no racismo institucional, aquele que aparece como um conjunto de mecanismos não percebidos socialmente e que permitem manter o negro em situação de inferioridade, sem que seja necessário que os preconceitos racistas se expressem, sem que seja necessária uma política racista para fundamentar a exclusão ou a discriminação. O sistema, nessa perspectiva, funciona sem atores, por si próprio (WIEVIORKA, 2006 apud SCHUCMAN, 2014).

Quando é proposto o questionamento do sistema que gera o racismo, ou reflexões sobre modos de subvertê-lo, não basta apenas perceber que um não está no outro, que o branco não está no negro, ou que existe uma longa distância entre eles, mas sobretudo identificar os mecanismos que perpetuam

3 O termo é utilizado aqui como propõe Schucman (2014): consideramos racismo qualquer fenômeno que justifique as diferenças, preferências, privilégios, dominação, hierarquias e desigualdades materiais e simbólicas entre seres humanos com base no conceito de raça. 
essa distância, sem neles se inserir. Um primeiro passo necessário, então, é abandonar a categorização do negro como "o outro", pois, em um mundo relacional e racista, é justamente essa a categorização que fundamenta um processo de racialização unilateral que acaba por gerar discriminação e preconceito.

Branco se constitui assim como uma experiência violenta para brancos que se enxergam na posição de impotência provocada pelo espetáculo, mas muito mais dolorosa para os negros que veem no teatro a reprodução dos sistemas que já os oprimem em tantos outros lugares da vida cotidiana. Identificar onde se encontram os privilégios é necessário, mais urgente, porém, é revelar e derrubar os pilares que os sustentam.

Em meio às polêmicas que tomaram as redes sociais após sua estreia, fica evidente que Branco: o cheiro do lírio e do formol proporciona experiências muito distintas para o público negro e para o público branco. Ainda que a subjetividade de cada espectador proporcione uma fruição única e individual, a condição coletiva que permeia a construção racial brasileira permite que negros e brancos desenvolvam pontos de vista muito específicos no que tange ao racismo. Escrevo esse texto, portanto, de um ponto de vista negro, do qual faço parte, e é desse mesmo ponto de vista que observo o cadáver deixado por Branco: o cheiro do lírio e do formol na cena teatral de 2017.

Poucos espetáculos recentes foram tão discutidos nas redes sociais, poucos foram objeto de tantas críticas, poucos foram tão dissecados pela academia. E o questionamento que fica após esse processo é: o que gerou tal movimentação? Há de se compreender que Branco surge em um momento crucial na história da luta contra o racismo no Brasil. Pela primeira vez, o negro começa a ocupar um lugar de fala - ainda assim, a muito custo - que Ihe foi por muito tempo negado. E é nesse contexto que um grupo de artistas brancos se propõe a falar sobre o racismo sem a presença do negro. É sabido que grupos formados por artistas negros discutem o racismo há décadas em seus trabalhos e não obtêm tamanha exposição. Nesse sentido, Branco se configura como uma obra importante no que tange a colocar a branquitude em cheque e, consequentemente, na luta contra o racismo. Desconstruir a branquitude é um passo primordial, assim como é, também, a presença do negro nesse processo. 
O que precipita, por fim, é uma obra de arte violenta, que adere ao tempo presente como um furacão, muito perigoso para aqueles que decidem se aproximar e devastador para o que existe a seu redor. Quando a tempestade passa, porém, e o sol começa a ressurgir, restam alguns corpos estendidos no chão e todos eles têm a mesma cor de pele. Resta também o incômodo de lidar com o que foi destruído. Resta a coragem de artistas que decidem saltar sem paraquedas no olho de um furacão. Não pense, no entanto, que essa coragem é minimamente similar à de um negro que precisa sair de casa todos os dias.

\section{Referências bibliográficas}

LIMA, E. T. Teatro negro, existência por resistência: problemática de um teatro brasileiro. Repertório, Salvador, n. 17, p. 82-88, 2011.

SCHUCMAN, L. V. Entre o encardido, o branco e o branquíssimo: branquitude, hierarquia e poder na cidade de São Paulo. São Paulo: Annablume, 2014.

WARE, V. O poder duradouro da branquidade: "um problema a solucionar." In: WARE, V. (Org.). Branquidade: identidade branca e multiculturalismo. Tradução Vera Ribeiro. Rio de Janeiro: Garamond; Afro, 2014. p. 7-40.

Recebido em 17/10/2017

Aprovado em 23/10/2017

Publicado em 26/12/2017 